Meta

Journal des traducteurs

Translators' Journal

\title{
Les avatars de marathon
}

\section{Noëlle Guilloton}

Volume 27, numéro 2, juin 1982

URI : https://id.erudit.org/iderudit/002988ar

DOI : https://doi.org/10.7202/002988ar

Aller au sommaire du numéro

Éditeur(s)

Les Presses de l'Université de Montréal

ISSN

0026-0452 (imprimé)

1492-1421 (numérique)

Découvrir la revue

Citer cet article

Guilloton, N. (1982). Les avatars de marathon. Meta, 27(2), 209-211.

https://doi.org/10.7202/002988ar

Ce document est protégé par la loi sur le droit d'auteur. L’utilisation des services d'Érudit (y compris la reproduction) est assujettie à sa politique d'utilisation que vous pouvez consulter en ligne.

https://apropos.erudit.org/fr/usagers/politique-dutilisation/
Cet article est diffusé et préservé par Érudit.

Érudit est un consortium interuniversitaire sans but lucratif composé de l'Université de Montréal, l'Université Laval et l'Université du Québec à Montréal. Il a pour mission la promotion et la valorisation de la recherche. https://www.erudit.org/fr/ 


\section{LES AVATARS DE MARATHON}

Tout le monde, sportif ou non, connaît le marathon, cette épreuve d'athlétisme qui consiste en une course de $42,195 \mathrm{~km}$, la plus longue des courses à pied.

Cette course de grand fond doit, comme chacun sait, son nom à la ville grecque de Marathon (proprement «champ de fenouil») d'où un soldat, Philippidès, gagna Athènes à la course pour annoncer la nouvelle de la victoire remportée par les Grecs sur les Perses en 490 av. J.-C. L'histoire - ou la légende - affirme en outre qu'il mourut d'épuisement à l'arrivée.

Les curieux des faits de langue ont sûrement noté, en Amérique du Nord, la prolifération de nouveaux mots comportant le suffixe populaire, fantaisiste et «bâtard " ${ }^{1}$-thon (et sa variante -ton). Il s'agit bien là de l'isolement artificiel de la dernière syllabe du toponyme grec, car pas plus que la langue anglaise orthodoxe, la langue française ne semble avoir gardé du grec l'élément thon, exception faite des mots thon (du grec thunnos), python (du grec pythôn) et de leur famille (du moins, à en croire le Dictionnaire inverse de la langue française $^{2}$, à la syllabe finale $-\mathrm{t} \hat{\mathrm{j}}$ ). La créativité débridée de la langue américaine a donc apporté, depuis la fin des années vingt, une pléthore de mots se terminant en -thon (ou, puisque l'américain aime simplifier, -ton), "nonce-words" pour certains, c'est-à-dire "termes forgés pour une occasion particulière et rarement employés ensuite ${ }^{3}$.

Avec les médias électroniques américains nous arrivent les téléthons (l'existence de «telethon» a été officialisée dans le Webster en 1961) et les radio-

1. Lajaunie, p. 308.

2. Juilland, p. 286-287

3. Lajaunie, p. 309. 
thons, au profit d'œuvres charitables de grande envergure. Les organismes plus modestes, à but lucratif ou non, organisent à qui mieux mieux des marchetons, nagethons, coursethons pour les sportifs, des huîtrotons, orguothons, orchestrothons pour les amateurs d'art culinaire ou musical, des tricothons et des bercethons pour les sédentaires et les pantouflards.

La liste de ces néologismes, qui semble infinie, peut en effet s'allonger au gré des activités et de l'imagination de chacun. Face à ce phénomène de profusion néologique américanisante, "on peut arguer que les composés en -thon comblent une lacune, puisqu'il n'existait avant eux aucune formule comparable exprimant aussi succinctement la même idée ${ }^{4}$, mais on est aussi forcé de s'interroger sur l'accueil qu'il convient de leur réserver.

S'agit-il de les adopter les yeux fermés au nom d'une certaine économie linguistique? Devrait-on en chercher des équivalents mieux formés, plus idiomatiques et qui témoignent des ressources de la langue française?

Voici toujours quelques exemples. Certains sont composés avec le mot marathon tout entier, puisqu'il a déjà, au figuré et par analogie avec la discipline olympique, le sens d'une épreuve prolongée dans n'importe quel domaine et qui exige une grande résistance; ce terme peut s'employer ainsi suivi d'un complément déterminatif introduit par la préposition de (marathon de danse), indifféremment comme deuxième élément de substantif composé ou en apposition, c'est-à-dire avec ou sans trait d'union (émission(-)marathon), ou bien encore suivi d'un adjectif déterminant (marathon cycliste). D'autres exemples prouvent qu'il est également possible de former des expressions avec les termes endurance (marche d'endurance), concours (concours de tricot) ou opération (opération verre perdu), qui possèdent eux aussi les traits sémantiques de compétition, d'épreuve, de pénibilité, de longue durée ou d'action menée par plusieurs personnes en concertation.

\author{
bercethon \\ berçothon \\ bouteillothon \\ chiffothon \\ coursethon \\ cyclothon \\ vélothon \\ gymnethon \\ harmoniothon \\ huîtroton \\ lavothon \\ marchethon \\ ménageothon
}

marathon en berceuses

opération verre perdu opération bouteilles vides opération vieux chiffons course d'endurance ${ }^{5}$ marathon cycliste marathon à bicyclette marathon à vélo marathon de gymnastique marathon d'harmonium dégustation marathon marathon gastronomique opération lave-auto marche d'endurance opération débarras

4. Ibid.

5. «Course marathon» serait une absurdité, puisque le marathon est d'abord une course. 
orchestrothon

orguothon

phonothon

paperthon

poolothon

poteauthon

radiothon

rockathon

téléthon

tennisothon

tricothon

\author{
marathon d'orchestre \\ marathon musical \\ marathon d'orgue \\ opération coup de fil \\ opération vieux papiers \\ match (de billard) marathon \\ concours de grimper \\ émission(-)marathon \\ marathon de rock ( $\mathrm{n}$ roll) \\ émission(-)marathon ${ }^{6}$ \\ match (de tennis) marathon \\ concours de tricot
}

De toute façon, ce n'est pas une affaire d'État, peut-être simplement une affaire de goût?

\author{
NoËLle GuILlotoN \\ (sans jeu de mots)
}

\title{
BIBLIOGRAPHIE
}

GILBERT, Pierre (1979): Dictionnaire des mots contemporains, Paris, (Les usuels du Robert), p. 332-333.

GILBERT, Pierre (1974) : « Marathon», Le Français dans le monde, $\mathrm{n}^{\circ} 107$, septembre, p. 5455.

JUILLAND, Alphonse (1965): Dictionnaire inverse de la langue française, The Hague, Mouton, p. 286-287.

LAJAUNIE, Marie-Andrée (1963): «Les suffixes émigrés aux États-Unis», Vie et langage, $\mathrm{n}^{\circ} 135$, juin, p. 308-309. 